\title{
Economics of healthcare financing in WHO South East Asia Region
}

\author{
Md. Anwarul Azim Majumder
}

Executive Editor, South-East Asia Journal of Public Health, Public Health Foundation, Bangladesh.

Lecturer, Department of Clinical Sciences, School of Medical Sciences, University of Bradford, West Yorkshire, Bradford, UK.

There are five broad ways of revenue collection for healthcare financing, namely, general revenue (taxation), mandated social health insurance contributions (usually salary-related and almost never risk-related), voluntary private health insurance contributions (usually riskrelated), out-of-pocket payment and donations. ${ }^{1}$ Most high income countries rely heavily on either general taxation or mandated social health insurance contributions, whereas low income countries depend far more on out-ofpocket (OOP) financing. ${ }^{1}$ Each country in the WHO South East Asia (SEA) Region adopts different ways of collecting revenue to finance healthcare.

Out-of-pocket health spending is the largest source of healthcare financing in most countries, especially those with low levels of government expenditure on health. In SEA Region, OOP expenditure is accounted for $84 \%$ of private expenditure on health ${ }^{2}$ and over $60 \%$ of total health expenditures in the region. ${ }^{3}$ The private expenditure on health as $\%$ of total expenditure on health in the region is $62.9 \%$ (Fig 1), which is the highest among WHO regions. $^{2}$ This is higher than low-income countries (61.1\%), lower-middle income countries (61\%) and global (40.8\%) contributions. ${ }^{2}$ In Bangladesh, OOP contribution continues to be two-thirds of the total health expenditure, which was $57 \%$ in $1996-97$ and became $64 \%$ in $2006-07 .^{4}$ In India, $71.1 \%$ of healthcare is financed through OOP payments by households at the time and point of healthcare use. ${ }^{5}$ Evidence shows that countries with a high share of OOP expenditures are more likely to have a high proportion of households facing absolute levels of catastrophic payments (defined as paying more than $40 \%$ of household income directly on healthcare after basic needs have been met) and impoverishment. $^{3}$

Out-of-pocket health payments have serious repercussions for health. ${ }^{3}$ It discourages vulnerable people from using services (particularly health promotion and prevention), and encourages them to postpone health checks. It has been estimated that over a billion people have no access to health services simply because they cannot afford to pay at the time they require them, while a 100 million people are pushed into poverty and 150 million people face financial hardship because they have to pay directly for the services at the point of delivery. ${ }^{6,7}$ The number of people who suffer financial catastrophes covers nearly $90 \%$ of the world's population. $^{7}$ Sometimes the costs are so high that households are unable to recuperate them from existing resources,

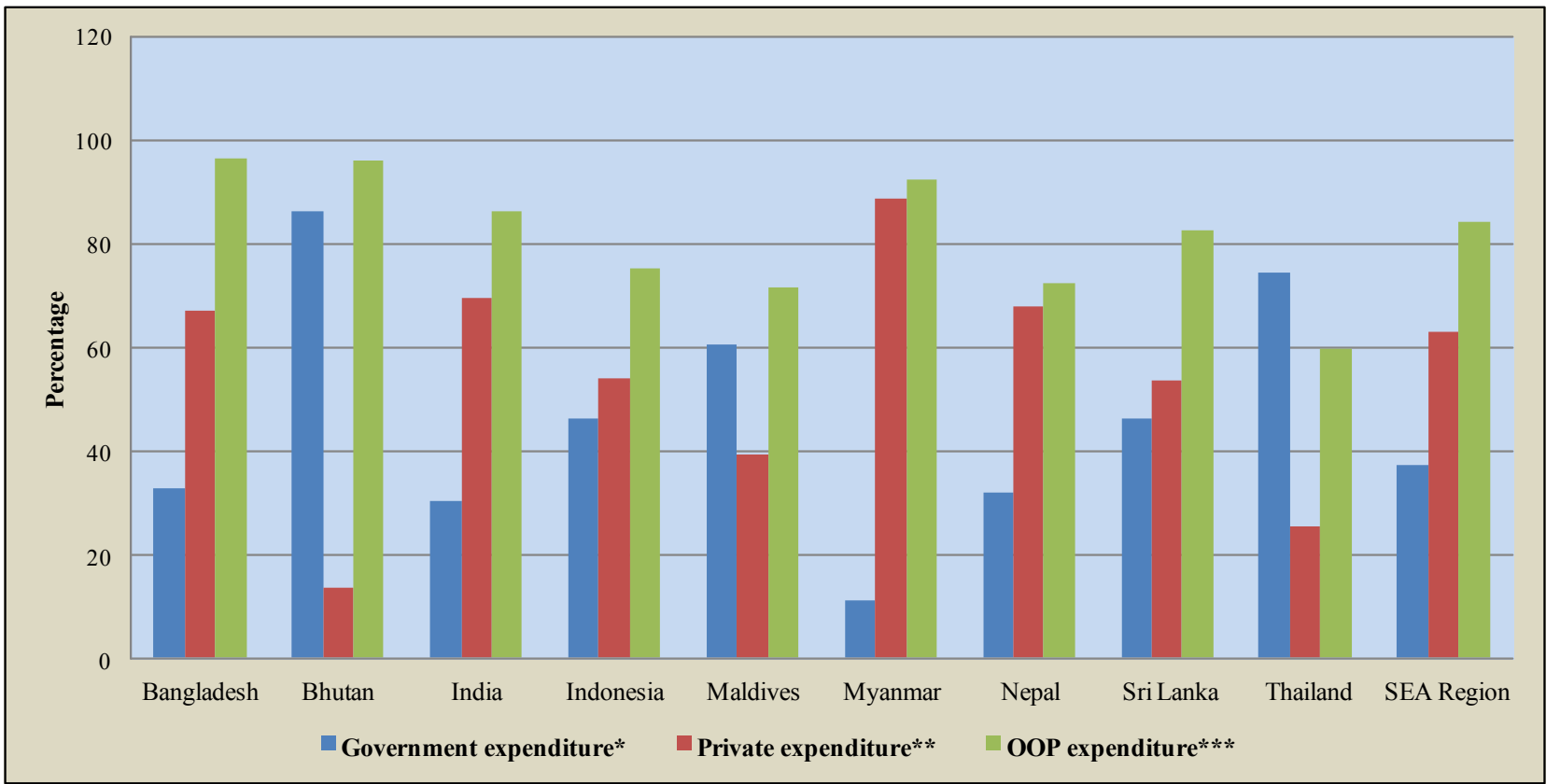

Fig 1. Healthcare financing in selected SEA Regional countries ${ }^{2}$

**General government expenditure on health as $\%$ of total expenditure on health; ** Private expenditure on health as $\%$ of total expenditure on health; *** Out-of-pocket expenditure as $\%$ of private expenditure on health.

Correspondence: Dr. Md. Anwarul Azim Majumder, Lecturer, Department of Clinical Sciences, School of Medical Sciences, University of Bradford, Bradford BD7 1DP, West Yorkshire, UK. E-mail: a.a.majumder@bradford.ac.uk, editor@phfbd.org.

South East Asia Journal of Public Health 2012;2(2):3-4. C 2012 Majumder, publisher and licensee Public Health Foundation Bangladesh. This is an Open Access article which permits unrestricted non-commercial use, provided the original work is properly cited. 
and hence ultimately slip deeper into poverty. Out-ofpocket payments pushed 100,000 households in both Kenya and Senegal below the poverty line in a single year. ${ }^{8}$ A study in India has clearly shown that OOP health expenditures were responsible for an average increase in poverty by as much as $3.6 \%$ and $2.9 \%$ for rural and urban India respectively. ${ }^{9}$ Policies and strategies should be designed to not only to increase access and utilization of services, but also to protect people from financial catastrophe, by reducing OOP spending. World Health Organization ${ }^{10}$ suggested strategies to cut OOP expenditure by extending population coverage through prepayment mechanisms; protecting the poor and disadvantaged; designing a benefits package; and deciding the level of cost sharing by the patients.

The health spending for SEA Region accounted for 3.8 $\%$ of gross domestic product (GDP) in 2008, below that of the averages for low-income countries (5.4\%), lowermiddle income countries $(4.3 \%)$, and the world $(8.5 \%) .{ }^{11}$ To attain universal coverage of health care, WHO proposed a number of target indicators: OOP spending should not exceed $30-40 \%$ of total health expenditure; total health expenditure should be at least 4$5 \%$ of GDP; over $90 \%$ of the population is covered by prepayment and risk-pooling schemes; and close to $100 \%$ coverage of vulnerable populations with social assistance and safety-net programmes. ${ }^{3}$ Out of 11 countries of the SEA region, 6 allocated less than $5 \%$ of GDP on healthcare. ${ }^{12}$ The share of public spending on health has decreased in the last 10-20 years as private healthcare has emerged rapidly in many countries. An important indicator of government's commitment to health is the share of government health expenditure in total health spending. Total general government expenditure on health as \% of total expenditure on health (2009) in the region was $37.1 \%$, which is lowest among all the WHO regions - less than low-income countries $(38.9 \%)$, lower-middle income countries $(39 \%)$ and global $(59.1 \%)$ averages. ${ }^{2}$ Limited resources often limit the amount of funds required to ensure universal coverage of necessary health interventions. Universal coverage ensures access for all citizens to appropriate promotive, preventive, curative, and rehabilitative services at an affordable cost. $^{6}$ To achieve universal coverage, countries need financing systems which guarantee necessary health interventions for the entire population without incurring financial hardship.

Improving health is critical to human welfare and essential to sustained economic and social development. To increase health investment and public spending on health, a comprehensive national policy on healthcare financing should be developed focusing on for adequate funding, efficiency of resource use, financial sustainability and capacity for better management of available resources. Poor and disadvantaged people should be protected from catastrophic health expenditures by reducing a health system's reliance on OOP and providing more financial risk protection. Higher public expenditures and better risk pooling mechanisms should also be identified as important financing mechanisms to bring down the share of OOP expenditures and also catastrophic impact of these payments.

Improving health is critical to human welfare and essential to sustained economic and social development. To increase health investment and public spending on health, a comprehensive national policy on healthcare financing should be developed focusing on for adequate funding, efficiency of resource use, financial sustainability and capacity for better management of available resources. Poor and disadvantaged people should be protected from catastrophic health expenditures by reducing a health system's reliance on OOP and providing more financial risk protection. Higher public expenditures and better risk pooling mechanisms should also be identified as important financing mechanisms to bring down the share of OOP expenditures and also catastrophic impact of these payments.

\section{References}

1. WHO. The World Health Report 2000: Health systems: improving performance. Geneva: World Health Organization, 2000.

2. WHO. World Health Statistics 2012. Geneva: World Health Organization, 2012.

3. WHO. Health financing strategy for the Asia Pacific region (2010-2015). Manila: World Health Organization, Regional Office for the Western Pacific, 2009.

4. DGHS. Health Bulletin 2010. Dhaka: Directorate General of Health Services, 2012.

5. National Health Accounts Cell. National Health Accounts India 2004-05. New Delhi: Ministry of Health and Family Welfare, Government of India, 2009.

6. WHO. The World Health Report: Health systems financing: the path to universal coverage. Geneva: World Health Organization, 2010.

7. $\mathrm{Xu} \mathrm{K}$, Evans DB, Carrin G, Aguilar-Rivera AM, Musgrove P, Evans T. Protecting households from catastrophic health spending. Health Aff (Millwood), 2007,26:972-83.

8. International Labour Organization Social health protection: An ILO strategy towards universal access to health care. Geneva: International Labour Organization, 2007.

9. Gupta I. Out-of-pocket Expenditures and Poverty: Estimates from NSS 61st Round. Draft paper. New Delhi: Institute of Economic Growth, 2009.

10. Xu K, Evans DB, Carrin G, Aguilar-Rivera AM. Designing health financing systems to reduce catastrophic health expenditure. Technical brief for policy-makers, Number 2. Geneva: World Health Organization, 2005.

11. Majumder MAA. World Health Statistics 2011: How does Bangladesh compare with other South -East Asian countries? South East Asia J Public Health 2011:1:3-8.

12. Rahman S, Majumder MAA. Health inequalities in South-East Asia - extent, causes, and principles for policy action. South East Asia J Public Health 2012;2:1-2. 